九州大学学術情報リポジトリ

Kyushu University Institutional Repository

\title{
Inheritance of Long Husk Leaves of Maize in Recombinant Inbred lines (RILs)
}

$\mathrm{Ji}$, Hee Chung

Grassland \& Forages Division, National Institute of Animal Science, Rural Development Administration

Yamakawa, Takeo

Laboratory of Plant Nutrition, Department of Plant Resources, Faculty of Agriculture, Kyushu University

https://doi.org/10.5109/12844

出版情報: 九州大学大学院農学研究院紀要. 53 (2)，pp.379-384，2008-10-28. Faculty of Agriculture, Kyushu University

バージョン :

権利関係 : 


\title{
Inheritance of Long Husk Leaves of Maize in Recombinant Inbred lines (RILs)
}

\author{
Hee Chung JI ${ }^{1}$ and Takeo YAMAKAWA* \\ Laboratory of Plant Nutrition, Division of Soil Science and Plant Production, \\ Department of Plant Resources, Faculty of Agriculture, Kyushu University, \\ 6-10-1 Hakozaki, Fukuoka 812-8581, Japan \\ (Received May 19, 2008 and accepted July 16, 2008)
}

\begin{abstract}
Husk leaves, surround and usually tightly enclose leaf sheaths, resulted in increase of yield production. Relative frequency distributions of visual husk leaves ratings on Hawaii M Set showed that most populations were skewed toward the lower values in the winter trial (2002) as well as in the spring trial (2003). Recombinant inbred lines (RILs) of Hawaii M Set were derived from inbred Hi38c1(bt) and Ia453 and the visual score ratings of husk leaves of their parents, Hi38c1(bt) and Ia453, were averaged 1.18 and 5.81, respectively.

The visual score ratings of husk leaves for the RILs were ranged from 1.0 to 7.5 with average of 2.15 . The length of husk leaf of the first ear showed positive correlation with that of second ear $(r=0.85, P<0.01)$. The number of tiller showed high correlation with the length of husk leaves in RILs of Hawaii M Set ( $r=0.45$, $\mathrm{P}<0.01$ ). Most of the RILs possessed characteristics of long husk leaves (lhls), prolificacy as well as tiller characters.

Breeding for maize with lhls and/or tillering appear to hold promise for improving silage maize yield, and especially sweet corn of $l h l s$ is useful for remove husk leaves prior to canning.
\end{abstract}

\section{INTRODUCTION}

The major contribution part of corn production is from leaves to the main stalk. However, in certain genotypes, some leaves may be extended from the modified leaf sheaths or husks surrounding the ear of maize. These leaves are referred to as "husk leaves" and they can significantly add potential photosynthetic products to the corn plant. They may be more efficient in the amount of photosynthates translocated to the kernels than other leaves. Most of tillering plant, grassy tillers $(g t)$ and tillered (tlr) mutant, have long husk leaves, and their characters contribute to somewhat for crop production. Especially $g t$ mutant have many tillers and long husk leaves (lhls) but corn grass $(\mathrm{cg})$ mutant have narrow waxy leaves and vegetative transformed ears and tassels.

Singleton (1949) has suggested that the ancestral form of modern corn is "corn grass". This anomalous type, the product of a single dominant gene, produces numerous tillers and small "ears" with a high proportion of single spikelet. A few researchers have studied the prospects for development of maize hybrids with multitillers and ears (MET). In order to improve the biological yield of modern maize hybrids, a different breeding approach has been attempted using land races with multiple tiller and ear habits (Choe et al., 1982, MNL 56:62). Toward the breeding of a new type of maize hybrid with MET, a few inbred lines with MET were developed and found that this tiller linked to umc 76 on the short of chromosome 1 (Lee et al., 1995). Jang et al. (2004)

${ }^{1}$ Grassland \& Forages Division, National Institute of Animal Science, Rural Development Administration, Cheonan, 330-800, South Korea

* Corresponding author (E-mail: yamakawa@agr.kyushu-u. ac.jp) cloned and characterized two genes (ZmRPS4, ZmMET1) that were strongly expressed in tiller base in MET.

Few have been reported on the genetics related to the presence of husk leaf and its length adapted for the Corn Belt Germplasm. Excess leaf tissue in the form of husk leaves may be somewhat analogous to excess glum and awn tissue in some cereal crops. In studies involving isogenic lines of barley, Qualset et al. (1965) showed that full and half-awned lines produced higher grain yields than quarter-awned and awnless lines. They reported that awns on a full-awned type contributed $19 \%$ of total grain yield.

Rasmusson and Crookston (1977) demonstrated that multiple-awn barley lines produced lower grain yield than normal awn barley lines. Jain (1971) found that $15 \%$ of the grain dry matter in a genotype could be attributed to the photosynthesis in the husk leaves. Sawada et al. (1994) demonstrated that the efficient contribution on grain production of husk leaves was not due to the photosynthetic rate of their leaves but to the efficient translocation of photosynthesis from them to ear. Because of the proximity of husk leaves to the ear, which is a major sink of photosynthates, the translocation of photosynthates from husk leaves to ear is more efficient than that from culm leaves.

The husk leaves comprise a small percentage of the total plant leaf area. But they may be beneficial in hybrid seed corn production fields where mechanical detasseling often remove a substantial amount of upper-leaf. The yield losses of the seed parent inbred have been estimated to be as much as $28 \%$ for the removal of three leaves along with the tassel. The amount of light intercepted by the husk leaves would increase and they may partially compensate for the reduced yield. Cantrell and Geadelman (1981) reported that for dent corn variety, even when husk leaves accounted for as much as $20 \%$ of an ear leaf, the decrease in grain yield by husk leaf 
removal was only about 2.6\%. Allison and Watson (1996) stated that the contribution of the husk leaves to photosynthesis was negligible under normal conditions but photosynthetic rate increased upon partial defoliation at the time of silking. Literatures on the genetics of this traits conferred by the husk leaves are spare.

The objective of our study was to know (1) frequency distributions of the length of husk leaves (2) the relationship between the husk leaves of the first- and the second-ear and (3) the relationship between husk leaves and tiller characters for 44 Recombinant Inbred Lines (RILs) of Hawaii M Set in sweet corn.

\section{MATERIALS AND METHODS}

\section{Plant materials}

Hawaii M Set of Recombinant Inbred Lines (RILs) was derived from the cross of inbreds Hi38c1(bt) and Ia453. Parent Hi38c1 is a conversion to brittle-1 allele of the sugary-1 inbred Hawaii AA8 and has non-husk leaves. A tropical inbred Ia453, Iowa inbred, is a conversion of the sugary-1 parent of the popular hybrids "Iochief" and has lhls and one or two tillers.

The procedure applied to develop RILs was the same as single-seed descent procedure based on the principle that only one seed (line) from each plant is used to advance to next generation in the absence of selection. The lines (ears) in the $\mathrm{S}_{6}$ generation were planted separately in row (one line per row) and then ten plants in each row (line) were sib-pollinated to produce seeds for the experiment in spring of 2002.

The Hawaii M Set and parents were planted twice on September 5, 2002 (trial 1) and February 27, 2003 (trial

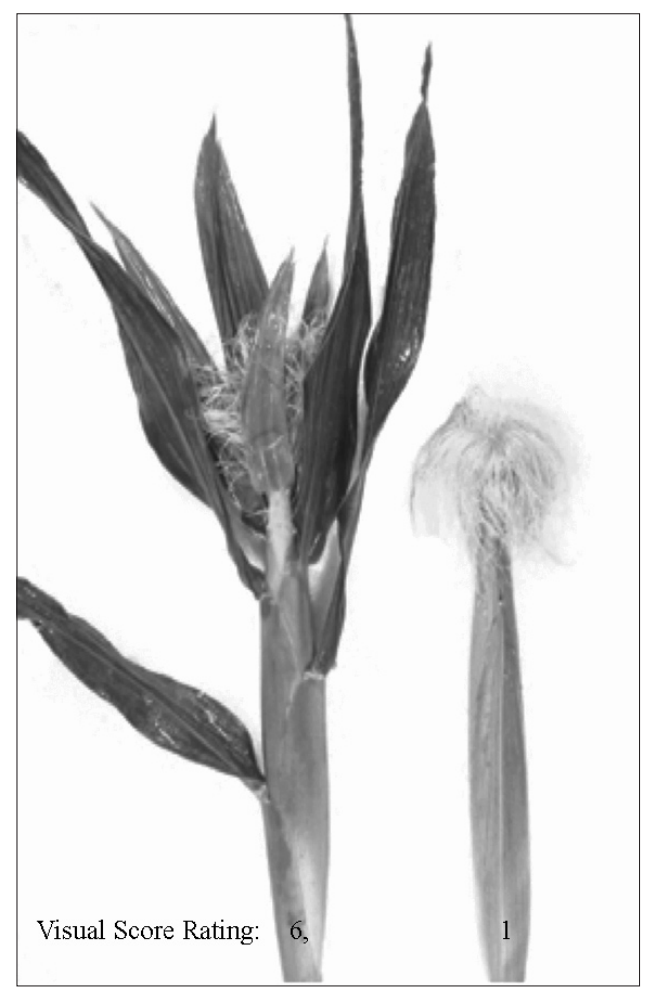

Fig. 1. Husk leaves of RILs of Hawaii M Set.
2) in Randomized Complete Block Design (RCBD) with drip irrigation at Waimanalo Research Station, University of Hawaii on Oahu at $21^{\circ} \mathrm{N}$ latitude and $30 \mathrm{~m}$ elevations. In each trial, each line was planted in each row (24 plants per $2.5 \mathrm{~m}$ row with $0.75 \mathrm{~m}$ between-row spacing) with 3 replications.

\section{Measurement methods}

Husk leaves of the primary ear were visually scored for each of five plants per Hawaii M Set line on a scale of 1 to 9 , with 1 indicating no visible husk leaves (less than $1 \mathrm{~cm}), 2$ indicating from 1 to $3 \mathrm{~cm}, 3$ indicating from 3 to $5 \mathrm{~cm}, 4$ indicating from 5 to $7 \mathrm{~cm}, 5$ indicating from 7 to $9 \mathrm{~cm}, 6$ indicating from 9 to $11 \mathrm{~cm}, 7$ indicating from 11 to $13 \mathrm{~cm}, 8$ indicating from 13 to $15 \mathrm{~cm}$, and 9 indicating very long husk leaves (more than $15 \mathrm{~cm}$ ) at approximately three weeks after slilking (Fig. 1). Frequency distributions of the visual scores of husk leaves were computed for all at two seasons. We also used another method to evaluate the length of husk leaves lhls. Husk leaves of the first- and the second-ear measured with a ruler for each of five plants per Hawaii M Set line.

\section{RESULTS AND DISCUSSION}

The average visual score ratings of husk leaves for the parents, Hi38c1(bt) and Ia453 were 1.18 (CV=33\%) and $5.81(\mathrm{CV}=34 \%)$, respectively (Table 1). RILs were derived from inbred Hi38c1(bt) and Ia453 that typify the difference between non-husk leaves and lhls. The average visual score ratings of husk leaves for 44 RILs of Hawaii M Set were 2.15, ranging from 1.0 to 7.5.

The visual score ratings of husk leaves of 44 RILs from Hawaii M Set during two year trials (2002 and 2003) were shown in Table 2. Among total 1982 sampled plants, there were 1544 plants (77.9\%) with short husk leaves and 438 plants (22.1\%) with lhls.

Days after silking (DTS) and days after anther (DTA) of Hi38c1(bt) were shorter than those of Ia453, and 100 kernel weight was a little lighter in Ia453 (8.5 \pm $0.56 \mathrm{~g})$ than in Hi38c1 $(10.62 \pm 0.54 \mathrm{~g})$, and ear length was somewhat longer in Hi38c1(bt) $(20.24 \pm 1.31 \mathrm{~cm})$ than in Ia453 $(18.74 \pm 1.15 \mathrm{~cm})$.

The data on husk leaf-length of the first ear showed

Table 1. Means and standard deviations of parental inbred, Hi38c1(bt) and Ia453, and 44 RILs of Hawaii M Set, ranges of RIL populations for visual score ratings of husk leaves

\begin{tabular}{lccc}
\hline \multirow{2}{*}{ Parameter } & \multicolumn{3}{c}{ Visual score rating $(1-9) \dagger$} \\
\cline { 2 - 4 } & 2002 & 2003 & AVG \\
\hline Hi38c1(bt) & $1.11 \pm 0.32^{*}$ & $1.25 \pm 0.43$ & $1.18 \pm 0.38$ \\
Ia453 & $5.54 \pm 1.98$ & $6.07 \pm 1.93$ & $5.8 \pm 1.96$ \\
RILs & $2.31 \pm 1.51$ & $1.98 \pm 1.30$ & $2.15 \pm 1.41$ \\
Range of RILs & $1.0-6.0$ & $1.0-9.0$ & $1.0-7.5$ \\
\hline
\end{tabular}

$\dagger$; Visual score rating (1-9): 1=non-husk leaves (less than $1 \mathrm{~cm}), 2=1$ to $3 \mathrm{~cm}, 3=3$ to $5 \mathrm{~cm}, 4=5$ to $7 \mathrm{~cm}, 5=7$ to $9 \mathrm{~cm}, 5=7$ to $9 \mathrm{~cm}, 6=9$ to $11 \mathrm{~cm}, 7=11$ to $13 \mathrm{~cm}, 8=13$ to $15 \mathrm{~cm}, 9=$ more than $15 \mathrm{~cm}$. *: Mean $\pm \mathrm{SD}$ 
Table 2. The visual score ratings and types of husk leaves for Hawaii M Set on Nov. 21, 2002 and May 12, 2003

\begin{tabular}{|c|c|c|c|c|c|c|c|c|c|c|c|}
\hline & 1 & 2 & 3 & 4 & 5 & 6 & 7 & 8 & $9^{\ddagger}$ & Mean $\pm S D$ & HLT \\
\hline M1 & $22^{\oplus}\left(14^{\#}\right)$ & 5 & 1 & & & & & & & $1.17 \pm 0.52$ & - \\
\hline M3 & 22(9) & $5(9)$ & 1 & 1 & & & & & & $1.41 \pm 1.93$ & $\mathrm{~N}$ \\
\hline M5 & $12(12)$ & $7(8)$ & 2 & & & & & & & $1.39 \pm 0.68$ & $\mathrm{~N}$ \\
\hline M6 & $2(4)$ & $11(9)$ & $7(5)$ & $2(2)$ & 2 & & & & & $1.70 \pm 1.06$ & $\mathrm{~N}$ \\
\hline M9 & 4 & $10(13)$ & $6(3)$ & $3(4)$ & & & & & & $1.88 \pm 0.93$ & M \\
\hline M12 & $10(11)$ & $13(9)$ & 3 & & & & & & & $1.48 \pm 0.61$ & W \\
\hline M13 & $13(13)$ & $9(4)$ & $3(1)$ & 1 & 1 & & & & & $1.42 \pm 1.81$ & - \\
\hline M14 & $22(15)$ & $3(5)$ & 1 & & & & & & & $1.22 \pm 0.80$ & $\mathrm{~N}$ \\
\hline M15 & $17(14)$ & $8(5)$ & 1 & & & & & & & $1.33 \pm 0.52$ & $\mathrm{~N}$ \\
\hline M16 & $10(3)$ & $15(12)$ & $2(4)$ & 1 & & & & & & $1.57 \pm 0.70$ & $\mathrm{~N}$ \\
\hline M17 & $1(1)$ & $12(10)$ & $6(7)$ & 2 & & & & & & $1.46 \pm 0.67$ & $\mathrm{~N}$ \\
\hline M18 & & $9(6)$ & $6(5)$ & $1(4)$ & 5 & & & & & $2.17 \pm 0.84$ & $\mathrm{~N}$ \\
\hline M19 & $27(7)$ & $2(6)$ & 3 & 3 & 1 & & & & & $1.43 \pm 1.00$ & - \\
\hline M21 & $24(14)$ & 6 & & & & & & & & $1.23 \pm 0.34$ & - \\
\hline M22 & 5 & $13(7)$ & $5(5)$ & $1(8)$ & & & & & & $1.91 \pm 0.92$ & $\mathrm{~N}$ \\
\hline M23 & $1(3)$ & $2(2)$ & $2(1)$ & $9(2)$ & $8(1)$ & (2) & 3 & $1(1)$ & (8) & $4.89 \pm 2.50$ & M \\
\hline M24 & & $(7)$ & (9) & (4) & 2 & & & & & $1.95 \pm 0.95$ & M \\
\hline M25 & $24(13)$ & $2(7)$ & & & & & & & & $1.26 \pm 0.40$ & - \\
\hline M26 & $11(6)$ & $11(7)$ & $2(5)$ & $2(2)$ & & & & & & $1.57 \pm 0.94$ & W \\
\hline M27 & 4 & $6(7)$ & $7(7)$ & $4(6)$ & 3 & & & & & $2.00 \pm 1.08$ & $\mathrm{~N}$ \\
\hline M28 & $10(8)$ & $6(9)$ & $6(1)$ & $1(1)$ & $2(1)$ & & & & & $1.64 \pm 1.16$ & $\mathrm{~N}$ \\
\hline M29 & $9(12)$ & $8(6)$ & $3(1)$ & $2(1)$ & & & & & & $1.52 \pm 0.91$ & M \\
\hline M30 & $10(7)$ & $11(2)$ & $4(1)$ & $3(5)$ & 3 & 2 & & & & $2.19 \pm 1.48$ & M \\
\hline M32 & $18(6)$ & $8(7)$ & $3(4)$ & 3 & & & & & & $1.41 \pm 0.91$ & $\mathrm{~N}$ \\
\hline M33 & $13(5)$ & $6(7)$ & $3(2)$ & $4(6)$ & & & & & & $1.89 \pm 1.17$ & M \\
\hline M35 & 4 & $5(8)$ & $6(5)$ & $5(7)$ & & & & & & $2.03 \pm 0.98$ & W \\
\hline M36 & 3 & 6 & 11 & $4(4)$ & (11) & (4) & (1) & & & $3.09 \pm 1.42$ & M \\
\hline M38 & (13) & $9(7)$ & 13 & & & & & & & $1.14 \pm 0.79$ & M \\
\hline M39 & & & 10 & $12(5)$ & (4) & (3) & (1) & (3) & (4) & $4.19 \pm 1.93$ & M \\
\hline M41 & $22(6)$ & $2(11)$ & $1(1)$ & (1) & (1) & & & & & $1.47 \pm 0.69$ & - \\
\hline M42 & $2(3)$ & $6(7)$ & $6(4)$ & $2(1)$ & $1(1)$ & (4) & & & & $2.16 \pm 1.48$ & $\mathrm{~N}$ \\
\hline M43 & & & & & (6) & (11) & (3) & & 4 & $6.50 \pm 0.67$ & $\mathrm{~N}$ \\
\hline M45 & $11(18)$ & $2(2)$ & & 1 & & 1 & & & & $1.43 \pm 1.03$ & M \\
\hline M48 & $18(1)$ & $10(8)$ & $(5)$ & (6) & & & & & & $1.71 \pm 1.01$ & $\mathrm{~N}$ \\
\hline M50 & $13(8)$ & $7(11)$ & $4(1)$ & & & & & & & $1.36 \pm 0.65$ & $\mathrm{~N}$ \\
\hline M51 & $1(5)$ & $5(3)$ & $4(4)$ & $7(5)$ & $2(3)$ & & 1 & & & $2.63 \pm 1.29$ & $\mathrm{~N}$ \\
\hline M53 & $17(11)$ & $4(8)$ & $2(1)$ & & & & & & & $1.28 \pm 0.62$ & - \\
\hline M54 & (9) & $2(4)$ & $4(5)$ & $8(2)$ & 6 & 2 & & & & $2.52 \pm 1.51$ & W \\
\hline M56 & (2) & (1) & & $1(9)$ & $8(4)$ & $9(2)$ & $1(2)$ & & & $4.97 \pm 1.39$ & M \\
\hline M57 & & (2) & $8(7)$ & $16(5)$ & $2(2)$ & 4 & & & & $2.93 \pm 0.96$ & M \\
\hline M61 & $23(6)$ & 4 & & & & & & & & $1.16 \pm 0.33$ & - \\
\hline M62 & $19(14)$ & $6(4)$ & 2 & & $1(1)$ & (1) & & & & $1.50 \pm 1.12$ & M \\
\hline M64 & (4) & $4(4)$ & $4(5)$ & $5(6)$ & $6(1)$ & & & & & $2.62 \pm 1.26$ & $\mathrm{~N}$ \\
\hline M66 & $1(1)$ & (4) & $2(5)$ & $5(7)$ & $3(3)$ & 1 & & & & $3.03 \pm 1.21$ & $\mathrm{~N}$ \\
\hline Hi38c1 & $18(22)$ & $1(4)$ & & & & & & & & $1.18 \pm 0.31$ & M \\
\hline Ia453 & & & & (1) & $9(11)$ & $13(10)$ & $5(2)$ & 1 & & $5.81 \pm 0.78$ & M \\
\hline Total & 767 & 519 & 258 & 213 & 115 & 69 & 19 & 6 & 16 & & \\
\hline
\end{tabular}

\#: winter trial (2002). @: spring trial (2003). $¥$ : visual score rating of husk leaves ( $1=$ less than $1 \mathrm{~cm}, 2=$ from 1 to $3 \mathrm{~cm}, 3=$ from 3 to $5 \mathrm{~cm}, 4=$ from 5 to $7 \mathrm{~cm}, 5=$ from 7 to $9 \mathrm{~cm}, 6=$ from 9 to $11 \mathrm{~cm}, 7=$ from 11 to $13 \mathrm{~cm}, 8=$ from 13 to $15 \mathrm{~cm}, 9=$ more than $15 \mathrm{~cm})$. HLT: husk leaf type, N: narrow husk leaves (less $5.5 \mathrm{~cm}$ ), M: medium husk leaves (between 5.5 and $9.5 \mathrm{~cm}$ ), W: wide husk leaves (more than $9.5 \mathrm{~cm})$.

positive correlation with those of the second ear $(\mathrm{r}=0.85$, $\mathrm{P}<0.01$ ) (Fig. 2). We could find that these husk leaves affects each other, and most of 44 RILs from Hawaii M Set had characteristics of multiple ears or prolificacy (possess more than one ear per plant in each line).

High relationship between tiller number and length of husk leaves in the RILs of Hawaii M Set ( $r=0.68$, $\mathrm{P}<0.01$ ) was shown in the Fig. 3. This result indicated that plant with lhls is likely to have tillering characteristics. Although tillering has been a teosinte-specific character, it has been affected by environment. That could explain for the tillering of the maize inbred used here even they were non-tillering (single main culm). Although the frequency distribution of the husk leaflength of the first ear on RILs population of Hawaii M Set had small difference from normality (Fig. 4), departing notably for values from 0 to $2 \mathrm{~cm}$ (higher than expected one). In general, there was generally a bell-shaped normal distribution. Most of the husk leaf-length of the first ear were longer than those of the second ear. That means the husk leaf-length of the second-ear depends on those of the first-ear but these data didn't always 


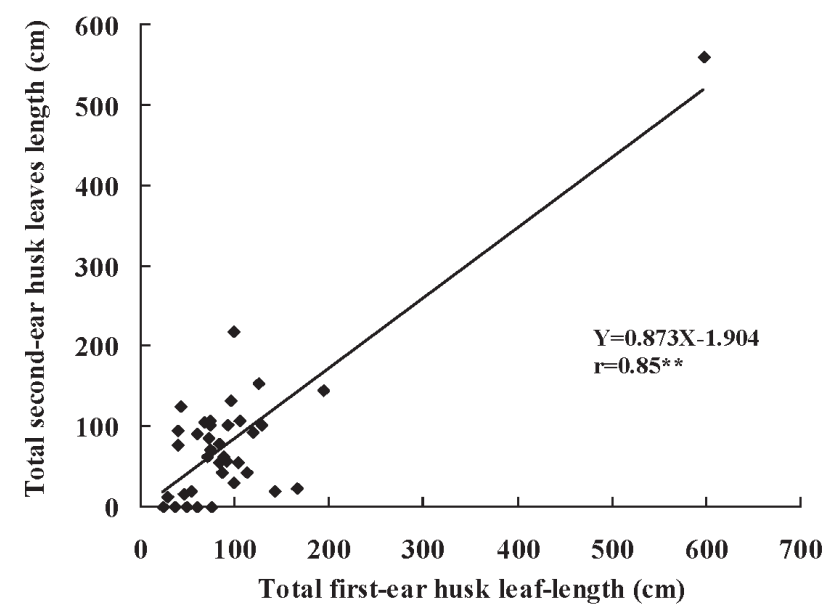

Fig. 2. The relationship between the husk leaf-length of the firstand the second-ear in 44 RILs of Hawaii M Set. **: significant at $\mathrm{P}<0.01$.

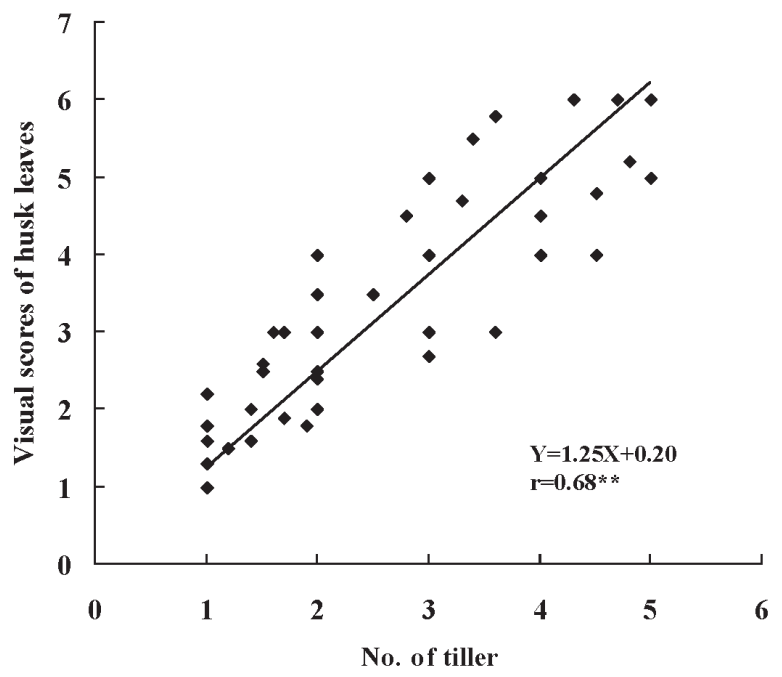

Fig. 3. The relationship between tiller number and husk leaves in 44 RIL populations of Hawaii M Set. **: significant at $\mathrm{P}<0.01$. showed the same relationship. The husk leaf-length of the second-ear sometimes appeared much longer than those of the first-ear. Because the husk leaf length of the first-ear has an apical dominance in $\mathrm{F}_{1}$ hybrids but those of the second-ear differ from the husk leaf-length of the first-ear. Most of the second-ear appeared well their characteristics due to affects less the first-ear as like apical dominance. Environment effect plays a major role in expression of tillering as well as husk-leaf length. The length of husk leaves vary depending upon environmental conditions such as growing space, light incident levels, temperature and day length. Field and tropical sweet corn is generally non-tillering (produces one main stem). The frequency distributions of the husk leaflength on 44 RILs population of Hawaii M Set in combined data during two year trials was skewed towards non-husk leaves type showed in Fig. 4

The husk leaves showed three types (narrow, medium and wide) and the number of RLIs be narrow, medium and wide type were 19, 15 and 4, respectively (Table 2). These types of husk leaves appeared either erect ear ecotype with efficient translocation of photosynthate or horizontal ear type.

The plant having lhls is very useful character in harvest process as well as photosynthesis, and contribute greatly to grain production (Cantrell and Geadelmann, 1981b), and the plants having this character are usually accompanied tillering and prolificacy. The husk leaves of RILs of Hawaii M Set segregated wide range (1 to 9), and showed highly correlated with tillering and prolificacy. The plants in spring trial showed more lhls characters than those in the winter trial. The husk leaves of the second-ear depended on those of the first-ear. However, for some RILs of Hawaii M Set has no husk leaves, the second-ear still showed lhls. The husk leaves evaluation of RILs in this study showed lhls was transferable by backcrossing. Breeding programs for lhls also considered prolificacy and tillering, because in most of the cases, those characters seem to act together and have influence on each other.

Simple selection method with high potential to

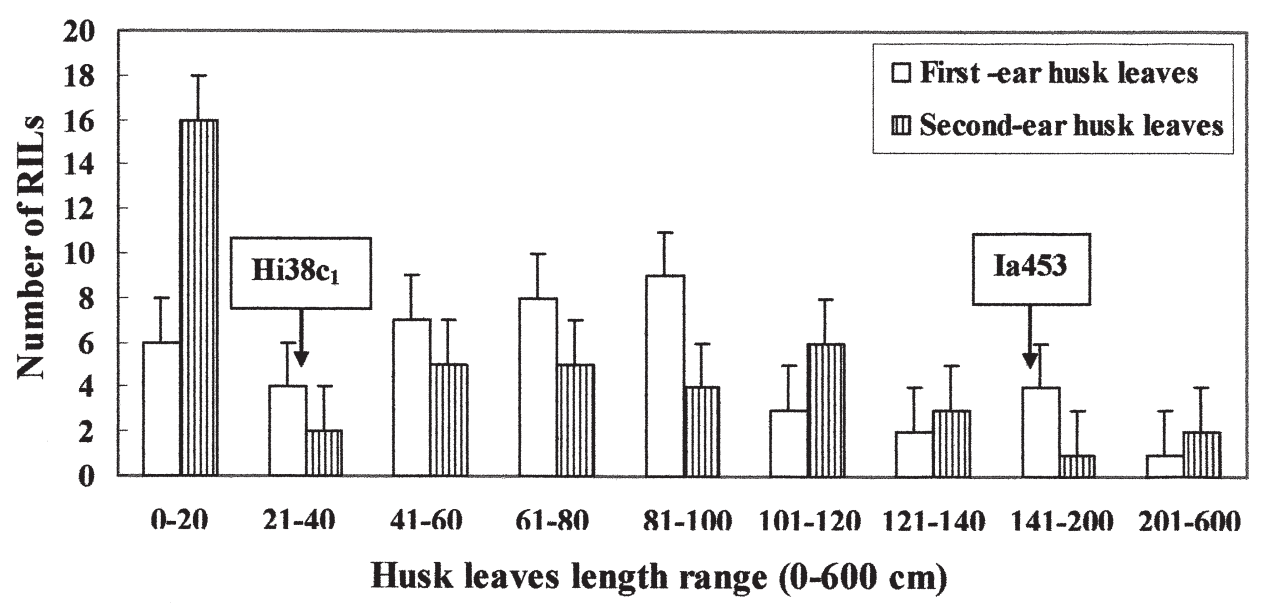

Fig. 4. Frequency distribution of the husk leaves length between the first- and the second-ear on RIL populations of Hawaii M Set. 
accelerate breeding progress for husk leaves in maize will gain wide acceptance if it can be economically competitive with present breeding methods. The study on tiller and husk leaves was still received less attention compared to that of other characteristics, and they have been studied separately. The husk leaves of RILs of Hawaii M Set showed three leaf types (narrow, medium and wide), and depend on their genetic background.

Most studies on husk leaves focused on yield contribution rather than basically genetic aspects. Sawada et al. (1995) demonstrated that the high efficiency of grain production of husk leaves was not due to the photosynthetic rate of leaves but to the efficient translocation of photosynthates from these leaves to ear. They explained that because of the proximity of husk leaves to the ear, which is a major sink of photosynthates, the translocation of photosynthates from husk leaves to ear is more efficient than that from culm leaves. It is well known that the photosynthesis of leaves on the main culm of corn is the $\mathrm{C}_{4}$ type. However, the husk leaves is reported to be $\mathrm{C}_{3}-\mathrm{C}_{4}$ intermediated type in terms of photorespiration rate (Langdale et al., 1988).

Maize tillering is one of the plant characteristics that have been neglected and unwanted for breeding purpose. However, it has been continued the studies on some tillering maize (Lee and Choe, 1988, 1991; Choe et al., 1989, 1992; Lee et al., 1994; Ji and Choe, 1998a, 1998b, 1999), because those tillering maize are quite different from other general tillering maize reported by Neuffer and Hoisington (1987). The tillering is claimed to be not monogenic but multigenic and temperature dependent (Choe and Lee, 1991; Choe et al., 1993) and some of tillering hybrids produced greater dry matter than leading U. S. maize hybrids, non-tillering maize (Choe et al., 1998). Choe and Han (1984) reported that the tillering of the MET line had the cytoplasmic effects on the number of tillers and ears in Korea.

According to other tillering type maize, the maturing embryo is the only totipotent meristem that is produced during the life cycle of the plant. The perennialism (pe) is maintained because basal branches retain totipotency. The pe appeared to act the totipotency of basal branches. It was assumed that it might confirm pe to any strongly tillering type of maize. The $g t$, other mutant type of maize, causes the production of numerous small tillers at the base of the main culm that terminate in small female inflorescences. Shaver (1967) reported a mutant ' $g t 1$ ' for grassy tiller, which had numerous branches and showed vegetatively totipotent in combination with 'pe1' and " $i d 1$ ". The mutant " $i d 1$ " standing for indeterminate growth was reported by Singleton (1946).

The Ia453 inbred line with lhls showed a prolificacy. Prolificacy maize also appeared tillering character as like $g t, c g$ and pe mutant so on, and showed long shank traits as Ia453 inbred.

NE-EDRsh2, another inbred line with lhls, also appeared tillering and lhls traits in Hawaii. We could assume that their three traits (tillering, long husk leaves, indeterminate growth) highly correlated with each other (data not shown) like $g t, c g$ and pe mutant. Firstly, in breeding for maize of $l h l s$, we must consider whether prolificacy traits eliminate or not, because these traits always have interaction with each other. Secondly, disadvantage traits, which maize of lhls sometimes have tip unfilled, small ear, irregular ear-row characters, long shank, and prolificacy, should be considered for breeding purpose in advance.

Breeding for lhls or tillering maize seems to be more advantage for silage production than grain yield increasing. Based on the results from this study, it is expected that tillering and lhls play an important role in improving silage maize yield, and especially sweet corn with $\mathrm{lhls}$ and also be useful for machine-handling prior to canning.

\section{REFERENCES}

Allison, J. C. S. and D. J. Watson 1996 The production and distribution of dry matter in maize after flowering. Ann. Bot. 30: $365-381$

Choe, B. H. and C. D. Han 1984 Influence of cytoplasm on tiller and ear number of a Korean local maize line. Maize Genetic Newsletter, 58: 85

Choe, B. H. and K. Park 1982 A maize line with high tillers and ears. $M N L, \mathbf{5 6}: 62$

Choe, B. H., K. K. Kang, W. K. Lee and H. B. Lee 1989 Tiller angels of maize with tillers. Maize Genetic Newsletter, 63 75

Choe, B. H. and H. B. Lee 1991 Effects of temperature on tillering behavior of tillering maize. Korean J. Breed., 20 $270-282$

Choe, B. H., H. B. Lee and W. K. Lee 1992 Agronomic characteristics of maize inbreds with tillers and their hybrids. Korean J. Breed., 23: 265-268

Choe, B. H., H. B. Lee, W. K. Lee, H. C. Ji and M. K. Baek 1993 Tillering depends on temperature. Maize Genetic Newsletter, 67: 108

Cantrell, R. G. and J. L. Geadelmann 1981a Inheritance of husk leaves in maize. Crop Sci., 21: 541-544

Cantrell, R. G. and J. L. Geadelmann 1981b Contribution of husk leaves to Maize Grain Yield. Crop Sci., 21: 544-546

Jang, C. S., H. B. Lee and Y. W. Seo 2004 Molecular characterization of two genes, ZmRPS 4 and ZmMET1, expressed in the tiller bases in maize. Maydica, 49: 137-142

Lee, H. B. and B. H. Choe 1988 II. Agronomic characteristics of maize (Zea mays L.) with multiple ears and tillers (MET). Korean J. Breed., 20: 270-282

Lee, H. B., W. K. Lee, I. S. Lee, B. H. Choe and S. K. Chung 1994 Tillers taller than the main stem are heritable. Maize Genetic Newsletter, 68: 100

Lee, H. B., E. H. Coe, G. Davis and B. H. Choe 1995 Gene for multi-tillers and ears. Maize Genetic Newsletter, 69 $123-124$

Jain, T. C. 1971 Contribution of stem, Laminae and ears to the dry matter production of maize after ear emergence. Indian J. Agric. Sci., 41: 579-583

Ji, H. C. and B. H. Choe 1998a Combinin ability and heterosis of major characteristics of tillering maize (Zea mays L.). Korean J. Breed., 30: 142-148

Ji, H. C. and B. H. Choe 1998b Effects of planting dates on tillering characteristics at different selfing generations of tillering maize. Korean J. Breed., 30: 232-242

Ji, H. C. and B. H. Choe 1999 Yield and growth characteristics of hybrid tillering maize at different planting densities. Korean J. Breed., 31: 200-208

Langdale, J. A., I. Zelitch, E. Miller and T. Nelson 1988 Cell position and light influence $\mathrm{C}_{4}$ versus $\mathrm{C}_{3}$ patterns of photo- 
synthetic gene expression in maize. EMBO J., 7: 3643-3651

Neuffer, M. G., Hoisington D. A. and. Bird R. Mck 1987 Designation of new dominant mutants. Maize Genetic Newsletter, 61: 50-51

Palmer, A. F. E., G. H. Herchel and R. B. Musgrave 1973 Patterns of translocation, respiratory loss and redistribution of C-14 in maize labeled after flowering. Crop Sci., 13: $371-376$

Qualset, C. O., C. W. Schaller and J. C. Wiliams 1965 Performance of isogenic lines of barley as influenced by awn length, linkage blocks and environment. Crop Sci., 5: 489-494
Ramusson, D. C. and R. K. Crookston 1977 Role of multiple awns in determining barley yields. Crop Sci., 17: 135-140

Sawada, O., J. Ito and K. Fujita 1995 Characteristics of photosynthesis and translocation of 13C-labelled photosynthate in husk leaves of sweet corn. Crop Sci., 35: 480-485

Schaller, C. W., C. O. Qualset and J. N. Rutger 1972 Isogenic analysis of the effects of the awn on the productivity of barley. Crop Sci., 12: 531-535

Shaver, D. L. 1967 Perennial maize. J. Hered., 58: 270-273

Singleton, W. R. 1949 Corn grass-a possible ancestral type of maize. Maize Genetic Newsletter, 23: 7-8 